Review

\title{
Involvement of Eukaryotic Small RNA Pathways in Host Defense and Viral Pathogenesis
}

\section{Julie Hicks and Hsiao-Ching Liu *}

Department of Animal Science, North Carolina State University, Raleigh, NC 27695, USA; E-Mail: jahicks3@ncsu.edu

* Author to whom correspondence should be addressed; E-Mail: hc_liu @ncsu.edu; Tel.: +1-919-515-4024; Fax: +1-919-515-6884.

Received: 23 September 2013; in revised form: 18 October 2013 / Accepted: 21 October 2013/ Published: 30 October 2013

\begin{abstract}
Post-transcriptional gene regulation by small RNAs is now established as an important branch of the gene regulatory system. Many different classes of small RNAs have been discovered; among these are short interfering RNAs (siRNAs) and microRNA (miRNAs). Though differences in the processing and function of small RNAs exist between plants and animals, both groups utilize small RNA-mediated gene regulation in response to pathogens. Host encoded miRNAs and siRNAs are generated from viral RNA function in host defense and pathogenic resistance in plants. In animals, miRNAs are key regulators in both immune system development and in immune function. Pathogens, in particular viruses, have evolved mechanisms to usurp the host's small RNA-mediated regulatory system. Overall, small RNAs are a major component of host defense and immunity in eukaryotes. The goal of this review is to summarize our current knowledge of the involvement of eukaryotic small RNA pathways in host defense and viral pathogenesis.
\end{abstract}

Keywords: small RNA; immunity; pathogens

\section{Small RNA Biogenesis}

There are several classes of small RNA families, and of these, short-interfering RNAs (siRNAs) and microRNAs (miRNAs) are the major small RNA groups associated with eukaryotic immunity. The biogenesis pathways of siRNAs and miRNAs are well conserved and greatly overlap (Figure 1). In the generation of both groups, a precursor molecule is processed into a short double-stranded RNA 
(dsRNA) duplex by a member of the Dicer family of endonucleases. However, in animals, primary miRNA transcripts, which can contain multiple miRNAs, are initially processed into single precursor miRNAs by the endonuclease, Drosha. For siRNAs, the precursor molecule for Dicer processing is a longer dsRNA, while the miRNA precursor is an RNA hairpin [1]. Currently, mammals are thought to have only a single Dicer; flies and worms encode two Dicers, while plants can have up to four Dicer-like endonucleases (DCLs), depending upon the species. In addition to its endonuclease activity, Dicer also functions as a helicase and separates duplex RNA into two single-stranded small RNA molecules [2]. One strand, often termed the guide strand, interacts with members of the Argonaute protein family to form the RNA-induced silencing complex, or RISC, while the other strand, called the passenger or star strand, is usually degraded. RISC then facilitates the interaction of the small RNA with its target sequence, resulting in silencing or suppression of gene expression, by one of several mechanisms, which will be briefly reviewed below.

Figure 1. Endogenous small RNA pathways involved in host defense and viral pathogenesis in plants and animals. (A) Small RNA biogenesis pathways mediated by the four Dicer-like endonucleases (DCLs) in plant cells. (1) DCL3 generates short interfering RNAs (siRNAs) from transcripts produced via RNA Pol IV-dependent transcription. These siRNAs then form a RNA-induced silencing complex (RISC) with Argonaute 4 (AGO4), which mediates chromatin modifications at complementary genomic DNA sites. (2) Plant primary-microRNA (pri-miRNA) transcribed by RNA Pol II is processed into a miRNA/miRNA* duplex by DCL1. The duplex is then transported to the cytoplasm by Hasty, a homolog of animal exportin-5, where the mature miRNA associates with Argonaute 1 (AGO1) to form a miRISC (miRNA-induced silencing complex). miRISC facilitates the degradation of targeted mRNAs. (3) RNA dependent RNA polymerase 6 (RDR6) produces dsRNAs from miRNA-mediated cleavage products of TAS gene transcripts. These dsRNAs are then processed into trans-acting siRNAs (tasiRNAs) by DCL4. Mature tasiRNAs form a RISC with AGO2 to mediate mRNA suppression. (4) Viral RNAs are utilized by RDR6 to produce dsRNAs, which are then processed into siRNAs by DCL2. These viral siRNAs undergo a second round of RDR6 amplification and are transported to peripheral sites, where they form RISCs with either AGO1 or AGO2. These RISCs then degrade viral RNA as part of the anti-viral response; (B) MicroRNA biogenesis pathway of animal cells. Pri-miRNAs transcribed from either cellular DNA or viral DNA via an RNA Pol II mechanism are processed into precursor hairpin molecules (pre-miRNA) in the nucleus. Pre-miRNAs are transported to the cytoplasm, where they are further processed into the mature miRNA, which associates with AGO2 and a several accessory proteins to form RISC. RISC then facilitates the suppression of mRNA expression. 
A

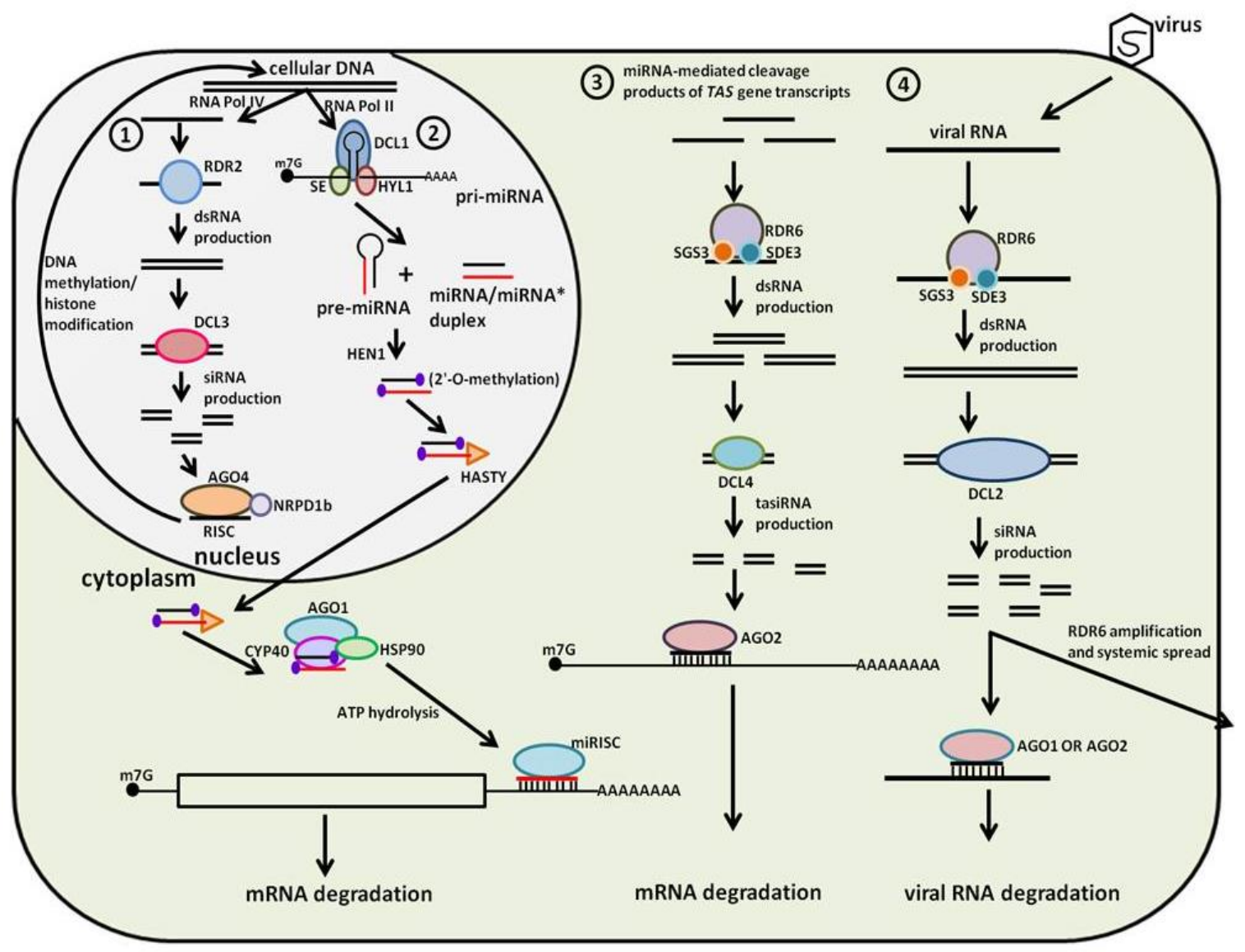

B

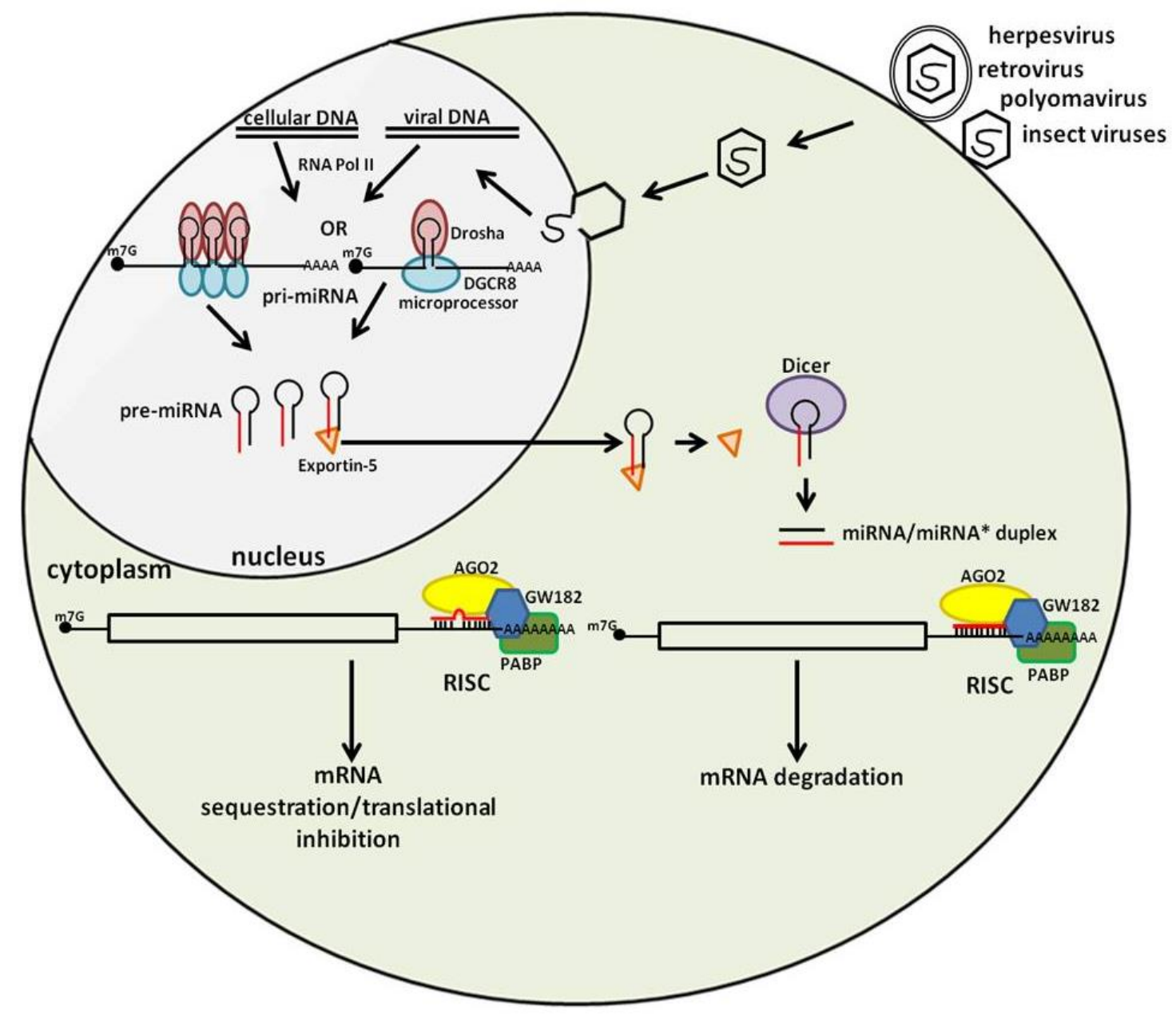




\section{Plant Small RNA: An Overview}

Plants produce a variety of small RNA species, which possess three main functions: (1) regulation of transposon activity; (2) pathogenic defense; and (3) regulation of intrinsic pathways, such as development and the response to environmental stresses [3]. Plants produce a variety of endogenous small RNAs. In general, plants encode four DCLs, each of which process distinct small RNA (sRNA) classes, but also share some overlapping or redundant functions (Figure 1B). DCL1 is involved in the generation of 21-22 nt sRNAs. DCL1 preferentially associates with hairpin precursor RNAs [3]. RNA processing by DCL2 results in small $22 \mathrm{nt}$ siRNAs. DCL3 generates sRNAs of $24 \mathrm{nt}$, while DCL4 is involved in the generation of $21 \mathrm{nt}$ sRNAs from precursors consisting of long prefect complementary dsRNA precursors [3]. DCL1 is mainly involved in miRNA processing and possesses functions analogous to both Dicer and Drosha in animals [4], while DCL2 and DCL4 are the major siRNA processors [5]. DCL2 siRNAs mainly function in host defense against viruses, though in the absence of DCL2, DCL4 can also produce antiviral siRNAs [6]. DCL3 siRNAs mainly regulate transposon activity and chromatin modification [4]. DCL4 processing is mainly reserved for trans-acting siRNAs (tasiRNAs). DCL4 tasiRNAs are mainly induced by and regulate the response to environmental stresses, such as drought. Plants encode approximately ten different Argonaute proteins (Agos), and similar to DCLs, these Agos have both distinct and overlapping functions (reviewed by [7]). AGO1 is the major Ago protein in miRNA RISCs. AGO2 interacts with tasiRNA generated from DCL4, while AGO4 is the main ago mediator of DCL3-processed siRNA function. A summary of RNA interference (RNAi) pathways in plants is shown in Figure 1A.

\section{Animal Small RNA: An Overview}

Animals also produce several distinct small RNAs, though not as many as the wide range found in plants. The major endogenous class of small RNAs involved in regulating the immune response and immune system development in animals consists of miRNAs. The other types of endogenous small RNAs are mainly involved in the regulation of development, particularly in embryos. In animals miRNA genes are mainly located in either the introns of protein-coding genes or are located in intergenic regions. Intergenic miRNAs are under the control of their own promoters, while intronic miRNAs most often are under the control of their host gene, though some intronic miRNAs have been found to have their own promoter. Though single miRNAs exist, miRNAs are often found in clusters in animal genomes. Many miRNAs are initially expressed as a single primary transcript, consisting of multiple pre-miRNA hairpins. These hairpins are individually released by Drosha. After Drosha processing, the miRNA hairpins are transported from the nucleus to the cytoplasm by an exportin protein. Once in the cytoplasm, the hairpin is further processed by Dicer, and the mature miRNA guide sequence is then loaded onto the RISC [2] (Figure 1B).

\section{Plant Immunity and Small RNA}

In contrast to animals, a major plant antiviral defense mechanism involves RNA silencing. Upon infection, viral dsRNA is recognized by DCLs and is cleaved into viral siRNAs (vsiRNAs) that are 21-24 nt in length [8]. These vsiRNAs are then amplified by host RNA-dependent RNA polymerases. 
The secondary population of siRNAs is then transported throughout the plant as part of the antiviral response. Of the four plant DCLs, DCL2 appears to be the major DCL associated with siRNA-mediated viral defense, though DCL4 may also contribute.

Plant PRRs (pathogen recognition receptors) are evolutionarily related to Toll-like receptors in animals [9]. They are typically receptor-like kinases. The resistance proteins involved in effector-triggered immunity are structurally analogous to Nod-like receptors in mammals. These resistance genes are intracellular molecules that function to survey the cytosol for pathogen-derived molecules. In plants, the chloroplast is also important in the immune defense. This defense is also involved in the production of oxidative species that are associated with hyper sensitive cell death response. The PAMPs (pathogen-associated molecular patterns) recognized by plant immune proteins are not necessarily pathogenic and are often structural [10]. For example, in A. thaliana, the PRR, FLAGELLIN SENSING 2, is a well-known receptor-like kinase involved in the detection of bacterial flagellin [10]. In addition to PRR/PAMP-triggered immunity, another major defense mechanism in plants is effector-triggered immunity (ETI). In ETI, a family of proteins, termed resistance or R proteins, recognize bacterial and viral antigens, which then triggers an immune response [11]. PRR/PAMP-triggered immunity and ETI are both regulated by and regulate small RNAs [12]. For example, bacterial infections can alter miRNA expression, including miR-393, miR-167, miR-160 and $m i R-825$ [13]. These miRNAs regulate the expression of auxin signaling genes, as well as biotic stress-related genes, which are associated with PAMP signaling. Also important in ETI are host-encoded resistance genes, termed nucleotide binding sites, and leucine-rich repeat resistance proteins, or NBS-LRR proteins. In healthy plants the expression of NBS-LRR proteins is regulated by $m i R-482$ [14]. However, when a plant becomes infected with either a virus or bacterium, miR-482 expression is downregulated, which then allows for increased expression of NBS-LRR proteins and induction of ETI. Melons express a member of the NBS-LRR protein family, Vat, which participates in the resistance to aphids [15]. MiRNA profiling during aphid infestations of resistant and susceptible plants revealed that, in general, miRNAs are upregulated in the resistant plants and downregulated in susceptible plants [15]. Many of the miRNAs upregulated in resistant plants regulate biotic and abiotic stress response genes. This data suggests that miRNA regulation is likely associated with disease resistance in plants. SiRNAs, such as nat-siRNAATGB2 and Atl-siRNA-1, are induced upon pathogenic infection and regulate the expression of several resistance genes [16]. In plants, siRNAs also play a role in the silencing of transposition by facilitating the methylation of transposable elements [6]. However, this mechanism requires the cooperation of histone deacetylase 6 (HDA6). In HDA6 mutant plants, siRNAs accumulate and induce de novo methylation, but this methylation does not result in the suppression of gene expression [6]. In the plant germline, there exists a special class of siRNA, which is termed epigenetically-activated $21 \mathrm{nt}$ siRNA, or easiRNA [17]. EasiRNAs are involved in the regulation of numerous host defense genes via epigenetic mechanisms.

\section{Animal Immunity and Small RNA}

The involvement of miRNAs in the regulation of immunity and the immune response is well characterized in animals. Analysis of miRNA expression and regulation in lymphocytic progenitors and in differentiated lymphocytes found that, on average, each of these cell types expresses $\sim 100$ 
different miRNAs [18]. CHIP-seq (chromatin immunoprecipitation sequencing) analysis further revealed that in lymphocytic progenitor cells, lymphocyte-specific expression of miRNAs is under epigenetic regulation and that these miRNAs are only fully expressed upon differentiation. In all, 50 miRNAs are upregulated upon lymphocyte maturation. MiRNA expression profiling of human primary macrophages found 119 expressed miRNAs. Several of the most highly expressed of these miRNAs, such as $m i R-146 a$ and $m i R-212$, are known to have immune-related functions [19].

Treatment of the acute myeloid leukemia cell line, THP-1 cells, with phorbol myristate acetate (PMA) to induce differentiation, was found to induce the expression of 23 PMA-regulated miRNAs [20]. Further analysis revealed that four of these miRNAs, $m i R-155, m i R-222, m i R-424$ and $m i R-503$, work in concert to induce cell-cycle arrest and differentiation of myeloid progenitor cells.

Several immune miRNAs have been well characterized; among these is $m i R-155$. There are currently over 100 studies published on $m i R-155$, the majority of which reveal its involvement in modulating the immune response and in immune cell proliferation. $\mathrm{CD} 8^{+} \mathrm{T}$-cells deficient for $m i R-155$ expression have reduced capacity to control viral infections [21]. This reduced efficacy of $\mathrm{CD} 8^{+}$ T-cells lacking miR-155 was linked to the accumulation of the miR-155 target, SOCS-1 (suppressor of cytokine signaling-1), which ultimately reduces STAT5 (signal transducer and activator of transcription 5) signaling [21]. MiR-155 expression is induced in murine macrophages following treatment with either polyriboinosinic:polyribocytidylic acid or IFN- $\beta$, suggesting a role for $m i R-155$ in the inflammatory response [22]. This increase in $m i R-155$ expression is facilitated by TLR (toll-like receptor) signaling. MiR-155 was identified as part of an IFN signaling feedback system, which is MyD88 and NFkB dependent [23]. Two other TLR-regulated miRNAs have also been identified, miR-21 and miR-146a [24]. MiR-155 expression can be induced by TLR2, TLR3, TLR4 or TLR9; miR-146a is responsive to TLR2-TLR5, and miR-21 is induced by TLR4 [25]. TLR signaling, in turn, can be regulated by miRNAs. TLR3 and TLR4 contain miR-223 binding sites [25]. TLR4 is also a target of let-7i and let-7c, while TLR2 is regulated by $m i R-105$.

Multiple studies have revealed a reciprocal relationship between NFkB and miRNAs, i.e., NFkB signaling regulates the expression of multiple miRNAs, and in turn, miRNAs regulate the expression of multiple members of $\mathrm{NF \kappa B}$ signaling. $\mathrm{NF \kappa B}$ signaling upregulates the expression of the pro-inflammatory cytokine, IL-6, by reducing let-7 expression, an IL6 regulator [26]. Conversely, $\mathrm{NF} \kappa \mathrm{B}$ upregulates the expression of both miR-146 isoforms, which reduce the expression of IRAK1/TRAF6, which then decreases NF- $\kappa$ B activity [27].

\section{Pathogenic Manipulation of Small RNA Pathways}

The majority of currently known viral miRNAs are encoded by herpesviruses, which encode between three (Herpes B virus) to 68 (Rhesus lymphocryptovirus) mature miRNAs [28]. Several studies have suggested that these herpesviral miRNAs are key regulators of viral latency. Examples of herpesvirus-encoded miRNAs and their function(s) in viral latency and transformation are given in Table 1. 
Table 1. Examples of virally-encoded miRNAs. KSHV, Kaposi's sarcoma-associated herpesvirus; HSV1, herpes simplex virus 1; MDV, Marek's disease virus; HCMV, human cytomegalovirus; EBV, Epstein-Barr virus; BLV, bovine leukemia virus; MICB, major histocompatibility complex class I polypeptide-related sequence B; ICP0, infected cell protein 0 .

\begin{tabular}{|c|c|c|c|}
\hline Virus & microRNA & Effect & Ref. \\
\hline HSV1 & $m i R-H 2-3 p$ & Targets viral $I C P O$; regulates latency & [29] \\
\hline KSHV & $m i R-K 12-4-5 p$ & Targets $R B L 2$; modulates epigenetic regulation & [30] \\
\hline KSHV & $m i R-K 12-7$ & Targets viral $R T A$; regulates latency & [30-33] \\
\hline KSHV & $m i R-K 9^{*}$ & Targets viral $R T A$; regulates latency & [33] \\
\hline HCMV & miR-UL112-1 & $\begin{array}{l}\text { Targets host restriction factor BclAf1; enhances } \\
\text { viral replication }\end{array}$ & {$[34,35]$} \\
\hline KSHV & $m i R-K 12-11$ & Hosts $m i R-155$ ortholog; regulates cell proliferation & [35] \\
\hline MDV1 & $\begin{array}{l}\operatorname{miR}-M 4 \\
\operatorname{miR}-B A R T 1-3 p\end{array}$ & $\begin{array}{l}\text { Hosts } m i R-155 \text { ortholog; regulates cell proliferation } \\
\text { orthologs to host miR-29a/b/c, miR-18a/b and }\end{array}$ & {$[36]$} \\
\hline EBV & $\begin{array}{l}m i R-B A R T 5-5 p \\
m i R-B A R T 22-3 p\end{array}$ & $\begin{array}{l}\mathrm{miR}-520 \mathrm{~d} / \mathrm{miR}-524-5 \mathrm{p} \text {, respectively; regulate } \\
\text { apoptosis and the cell cycle }\end{array}$ & [37] \\
\hline BLV & $b l v-m i R-B 4$ & $\begin{array}{l}\text { Hosts } m i R-29 \text { ortholog; contributes to viral-induced } \\
\text { lymphoma }\end{array}$ & [38] \\
\hline $\begin{array}{l}\text { KSHV, EBV, } \\
\text { HCMV }\end{array}$ & $\begin{array}{l}\text { miR-K12-7, } \\
\text { miR-BART2-5p, } \\
m i R-U L 112\end{array}$ & Target host MICB; virus immune evasion & [39] \\
\hline
\end{tabular}

Many herpesvirus miRNAs are located in genomic regions associated with viral latency. The latency associated transcript (LAT) of herpes simplex virus 1 (HSV1) encodes four miRNAs [29]. One of these miRNAs, $m i R-H 2-3 p$, is likely involved in latency regulation by targeting the viral gene, $I C P 0$, an immediate-early gene that is associated viral replication and reactivation [29]. Twelve miRNAs located in the latency-associated region (LAR) of Kaposi's sarcoma-associated herpesvirus (KSHV) are expressed during viral latency [30]. These miRNAs have also been linked to viral latency and reactivation. A host gene involved in the epigenetic regulation of $\mathrm{KSHV}, R B L 2$, as well as the viral gene, RTA (replication and transcription activator), a reactivation regulator, are targets of KSHV miRNAs [30]. RTA is an immediate early gene considered a lytic switch for reactivation of latent KSHV. The KSHV-encoded miR-K12-7 is able to regulate RTA expression via a recognition site within its 3' UTR (untranslated region) [31]. A KSHV deletion mutant lacking 10 KSHV miRNAs, including miR-K12-7, displayed increased expression of lytic genes, including RTA [32]. RTA is also likely regulated by another KSHV-encoded miRNA, termed $m i R-K 9 *$ [33]. Disruption of $m i R-K 9 *$ function in KSHB latently infected cells resulted in increased viral reactivation [33]. Together, these studies suggest that virally-encoded miRNAs are an important aspect in the maintenance of KSHV latency. MicroRNA sequence analysis of KSHV tumors revealed that some KSHV-encoded miRNAs are more susceptible to mutations than others [40]. The KSHV-encoded miRNAs, miR-K12-1, -3, -8, $10,-11$ and -12 were conserved between patients, while miR-K12-2, -4, -5, -6, -7 and -9 had much more inter-patient sequence variability, which could impact their functionality. Human cytomegalovirus (HCMV), which encodes 17 mature miRNAs, expresses a miRNA, termed miR-UL112-1, during the 
late stages of infection, which targets the host restriction factor, BclAfl [34]. This miRNA targeting and subsequent reduction in BclAf1 expression enhances viral gene expression and replication. BclAf1 has been shown to target the viral protein, IE1, as part of the host anti-viral response to HCMV [36]. These results suggest that HCMV miR-UL112-1 is involved in viral evasion of the host immune response. Multiple miRNAs have been identified in the genome of Marek's disease virus (MDV), a well-known herpesvirus of poultry. Oncogenic MDV strains, classified as MDV serotype 1 (MDV-1), encode 14 precursor miRNAs, which produce 26 mature miRNAs [28]. Expression studies have revealed that MDV-1 miRNAs are differentially expressed during infections with strains of varying virulence [36]. These studies have also shown that miRNAs located near $M E Q$, a known MDV oncogene, are expressed at higher levels in infections with highly virulent strains compared to less virulent strains. This differential expression has been linked to a polymorphism, which is the likely promoter of these viral miRNAs.

Several herpesviruses encode an ortholog to a host miRNA, miR-155, including KSHV and MDV. Currently, miR-155 is one of the most studied miRNAs, in part because it has been linked to lymphocyte development and is often upregulated in lymphomas and other cancers [41]. For example, it is well established that miR-155 expression is induced upon Epstein-Barr virus (EBV) infection of B-cells [42]. This upregulation of miR-155 is likely associated with EBV-induced transformation [43]. Recently, miR-155 has been linked to EBV latency regulation, as treatment of latent EBV infected cells with a miR-155 inhibitor reduces viral EBNA1 expression, which, in turn, reduces the EBV copy number [41]. In KSHV-infected lymphocytes, sustained expression of the KSHV miR-155 ortholog, $m i R-k 12-11$, likely contributes to the increased proliferation seen in these cells $[44,45]$. Typically, $m i R-155$ is low in KSHV-infected B-cells, while miR-k12-11 is highly expressed [44,45]. It has been demonstrated that $m i R-k 12-11$ functionally overlaps with $m i R-155$, as it is able to compensate for a lack of $m i R-155$ in knockout mice [46]. A miRNA located in the $M E Q$ cluster of MDV-1, $m d v 1-m i R-M 4$, is a $m i R-155$ ortholog [36]. Deletion or seed region mutagenesis of $m i R-M 4$ prevents lymphoma induction in infected birds [47], suggesting a role for $m i R-M 4$ in MDV oncogenesis. However, insertion of $m i R-M 4$ into a related, but non-oncogenic, virus, herpesvirus of turkeys (HVT), does not result in tumor formation in infected birds [48], suggesting that other factors are needed for viral transformation. In addition to the miR-155 ortholog, EBV encodes miRNAs sharing seed sequences with host $m i R-29 a / b / c, m i R-18 a / b, m i R-520 d-5 p$ and $m i R-524-5 p$ [49]. Target gene analysis using an AGO pull-down assay revealed that these homologous viral/host miRNAs share many of the same targets. These conserved targets are involved in regulating apoptosis, the cell cycle and Wnt signaling. The retrovirus bovine leukemia virus (BLV) also encodes a miR-29 ortholog, termed $b l v-m i R-B 4$ [37]. It was postulated that due to the shared targets of $m i R-29, b l v-m i R-B 4$ may contribute to BLV-induced B-cell lymphomas. Though herpesvirus-encoded miRNAs share little sequence similarity, it has been demonstrated that several human viruses have a conserved miRNA target gene. KSHV, EBV and HCMV all encode miRNAs, which target the host gene MHC class I polypeptide-related sequence B (MICB), a stress-induced immune ligand [38]. Virally encoded miRNAs were found to downregulate MICB expression during infection. It was suggested that this miRNA-mediated downregulation of MICB is part of the herpesvirus immune evasion strategy.

Several host miRNAs have also been linked to herpesvirus infections. The EBV encoded protein, LMP1 (latent membrane protein 1), induces the expression of host miR-34a upon EBV infection of 
human B-cells [39]. MiR-34a has also been found to be highly expressed in several EBV-transformed cell lines. Interestingly, $m i R-34 a$ is considered to be a tumor suppressor miRNA, whose expression is directly regulated by p53 [50]; however, increased $m i R-34 a$ levels are associated with enhanced growth in EBV-infected cells [39]. Two additional host miRNAs have been linked to EBV infections. The miRNAs, $m i R-200 b$ and $m i R-429$, were recently shown to be involved in the EBV lytic/latent switch [51]. Exogenous expression of $m i R-200 b$ and $m i R-429$ in EBV-positive cells results in increased expression of EBV lytic genes. MiR-200b and $m i R-429$, both members of the $m i R-200$ miRNA family, were shown to regulate the expression of $Z E B 1$ and $Z E B 2$, whose gene products are transcriptional repressors involved in IL2 regulation and previously shown to regulate EBV latency [52]. In addition, EBV infection of blood-derived human B-cells results in the decreased expression of $m i R-200 b$ [51]. In human $\mathrm{CD} 34^{+}$hematopoietic progenitor cells latently infected with HCMV, the host miRNA, miR-92a, is downregulated [53]. Decreased $m i R-92 a$ expression results in an increase in its target gene expression, GATA-2. This increase in GATA-2 results in increased IL-10 expression, suggesting that IL-10 may be involved in HCMV latency. Knockdown of miR-101 in HeLa cells increases HSV-1 production in infected cells [54]. MiR-101 was shown to target the host gene, $A T P 5 B$, an ATP synthase, and siRNA knockdown of ATP5B expression in HeLa cells greatly reduces HSV-1 production. Analysis of host miRNA expression in porcine dendritic cells upon infection with pseudorabies virus, an alpha herpesvirus, revealed multiple differentially-expressed host miRNAs [55]. These miRNAs regulate genes and pathways with shared functions. In an MDV-transformed T-cell line, MSB1, two related host miRNAs, $m i R-221$ and $m i R-222$, are significantly upregulated relative to splenocytes or $\mathrm{CD}^{+} \mathrm{T}$-cells [56]. Additionally, conserved binding sites for these miRNAs are identified in the 3' UTR of $p 27^{k i p 1}$, a known $m i R-221 / 222$ target in mammals. However, the overexpression of $m i R-221 / 222$ has not been found in other MDV-transformed cell lines, suggesting these miRNAs may not play a general role in MDV transformation. Overall, both viral and cellular miRNAs are important regulators during herpesvirus infections, particularly during the lytic/latent switch and transformation.

Polyomaviruses have also been found to encode miRNAs, though much fewer in number and variation than with herpesvirus miRNAs. Currently, all examined polyomaviruses encode a single miRNA precursor, which produces one or two mature miRNAs [28]. The majority of polyomavirusencoded miRNAs are located antisense to the large $\mathrm{T}$ antigen (Tag) and function in a siRNA-like manner in the regulation of Tag expression [57-60]. Unlike herpesviruses, many polyomavirus miRNAs share sequence homology. The miRNA precursors encoded by the related polyomaviruses, bandicoot papillomatosis carcinomatosis virus type 1 and 2, are located outside of the Tag gene, but were shown to still regulate Tag expression by binding to a complementary site in its 3' UTR [60]. SV40 (simian virus 40) miRNA Tag targeting reduced the cytotoxic T-lymphocyte (CTL) response [58]. Little is known about potential host gene targets of polyomavirus miRNAs. However, recently, the host gene, ULBP3, a stress-induced ligand, was identified as a target of JC virus and BK virus miRNAs [58]. This targeting has been suggested to be involved in immune evasion, as it is associated with reduced natural killer cell killing of virally infected cells. No noticeable differences between a mutant murine polyomavirus lacking the miRNA precursor and wild-type virus have been observed in vivo [59]. 
Though only a few viruses, including herpesviruses, polyomaviruses, retroviruses and several invertebrate viruses, have been found to encode miRNAs, most viruses have been found to manipulate host miRNA expression (examples are given in Table 2). Several host miRNAs, $m i R-28, m i R-125 b$, $m i R-150, m i R-223$ and $m i R-382$, are found at much higher levels in resting CD4 ${ }^{+} \mathrm{T}$-cells compared to activated cells [61]. The 3' UTRs of several HIV mRNAs contain multiple binding sites for these particular miRNAs, suggesting that host miRNAs may be involved in the maintenance of HIV latency in resting $\mathrm{CD}^{+}$T-cells (Table 2, [61]). Furthermore, these miRNA binding sites are conserved between HIV strains. One symptom of hepatitis B virus (HBV)-induced hepatic cirrhosis is splenomegaly. Expression analysis revealed that 99 miRNAs are differentially expressed between normal spleens and spleens exhibiting HBV-induced hypersplenism [62], suggesting host miRNAs are associated with HBV pathogenesis. A comparison of host miRNA expression differences during infection with any of the three influenza strains, H5N1 (also known as bird flu), a reconstructed 1918 H1N1 strain (r1918) and a seasonal H1N1 virus, suggests that miRNAs are involved in influenza pathogenesis [26]. The two highly pathogenetic strains, H5N1 and r1918 altered the expression of 23 host miRNAs that are not altered by the milder seasonal H1N1 [26]. A similar study comparing cellular miRNA expression differences between r1918 and a seasonal strain (A/Texas/36/91) in mice found that over a hundred miRNAs are affected differently between the two strains [63]. Among these miRNAs are $m i R-200 a$ and $m i R-223$, whose target mRNAs are involved in the immune response and cell death pathways associated with the severe immune response found in r1918-infected lungs [63]. Microarray analysis of miRNA expression of cells infected with any one of three influenza strains of varying pathogenicity found that during early infection, in vitro, relatively few host miRNAs are upregulated, with only $9 \%$ of differentially-expressed miRNAs being upregulated at 24 hours post-infection (hpi) [64]. However, at $48 \mathrm{hpi}$ and $72 \mathrm{hpi}$, the number of upregulated miRNAs is greatly increased, with over $90 \%$ of the differentially miRNAs being upregulated. Vaccinia virus (VACV), historically used in vaccinating against smallpox, was recently shown to induce a general downregulation of host miRNA expression in infected cells [65]. This downregulation of miRNA expression occurs within 24 hours of infection and is linked to a decrease in Dicer, a miRNAprocessing enzyme, expressed in VACV-infected cells. The flavivirus, Dengue virus, also downregulates the expression of Dicer, along with other RNAi enzymes, including Drosha, AGO1 and AGO2 [66]. This reduction in RNAi proteins is linked to the viral protein, NS4B. Reduction of RNAi activity increases viral replication, suggesting that NS4B downregulation of RNAi proteins is part of the virus host defense against Dengue virus [66].

One of the most well-characterized examples of pathogen manipulation of host miRNAs is that of hepatitis $\mathrm{C}$ virus (HCV) and its use of the host liver-specific miRNA, miR-122 [67]. Numerous profiling studies have shown that $m i R-122$ is highly expressed in the liver and functions in the regulation of lipid and cholesterol metabolism [68]. HCV has limited tropism in vitro, with very few permissive cell lines available. It was shown that a cell line permissive to HCV infection expresses high levels of $m i R-122$, while non-permissive cell lines do not express $m i R-122$ [67]. When $m i R-122$ function is inhibited in the permissive cell line, HCV replication is greatly reduced. Ectopic expression of $m i R-122$ in non-permissive cell lines does support viral replication; however, no HCV infectious particles are produced [69]. In silico analysis predicted a $m i R-122$ binding site within the 5' UTR of the $\mathrm{HCV}$ genome, and mutational analysis confirmed that the binding of $m i R-122$ to this site enhances 
HCV replication [67]. It was recently shown that this enhanced viral replication is not due to a direct effect of $m i R-122$ on HCV RNA synthesis, as cells transfected with a miR-122 inhibitor have lower levels of HCV RNA, but do not have reduced HCV RNA synthesis [70]. Instead, the interaction between $m i R-122$ and the HCV genome is likely important in stabilizing viral RNA [71].

Table 2. Examples of the involvement of cellular small RNAs in viral infections. HCV, hepatitis $\mathrm{C}$ virus; RGDV, rice gall dwarf virus; PSTVd, potato spindle tuber viroid; TSWV, tomato spotted wilt virus; CMV, cucumber mosaic virus; TEV, tobacco etch virus; TBSV: tomato bushy stunt virus.

\begin{tabular}{|c|c|c|c|c|}
\hline Virus & Effector Molecule & Targets of interest & Effect on virus & Reference \\
\hline EBV & $m i R-155$ (induced) & & $\begin{array}{l}\text { Associated with viral } \\
\text { transformation }\end{array}$ & [41-44] \\
\hline EBV & $\begin{array}{l}m i R-34 a \text { (induced by } \\
\text { EBV LMP1) }\end{array}$ & & Enhanced viral growth & {$[50,51]$} \\
\hline EBV & $m i R-200 b, m i R-429$ & ZEB1, ZEB2 & Regulation of viral latency & {$[52,53]$} \\
\hline HCMV & $\begin{array}{c}m i R-92 a \\
\text { (downregulated) }\end{array}$ & GATA-2 & $\begin{array}{l}\text { Increased IL-10, involved } \\
\text { in viral latency }\end{array}$ & [54] \\
\hline HSV1 & $\begin{array}{c}m i R-101 \\
\text { (downregulated) }\end{array}$ & ATP5B & Enhances virus replication & {$[55]$} \\
\hline $\begin{array}{l}\text { MDV (MSB1 } \\
\text { cell line) }\end{array}$ & $m i R-221, m i R-222$ & $\mathrm{p} 27^{\mathrm{Kip} 1}$ & $\begin{array}{l}\text { Associated with viral } \\
\text { transformation }\end{array}$ & {$[57]$} \\
\hline HIV & $\begin{array}{c}m i R-28, m i R-125 b, \\
m i R-150, m i R-223, \\
m i R-382\end{array}$ & multiple HIV genes & $\begin{array}{l}\text { Maintenance of latency in } \\
\text { resting T-cells }\end{array}$ & {$[62]$} \\
\hline $\mathrm{HCV}$ & $m i R-122$ & $\begin{array}{l}\text { Interacts with the } \mathrm{HCV} \\
\text { genome }\end{array}$ & Enhances viral replication & [68-70] \\
\hline Dengue & NS4B & $\begin{array}{c}\text { Downregulates Dicer, } \\
\text { Drosha, AGO1 and AGO2 }\end{array}$ & Enhances viral replication & {$[67]$} \\
\hline TSWV & Viral NS proteins & $\begin{array}{c}\text { Binds to dsRNA } \\
\text { and blocks } \\
\text { Dicer-mediated cleavage }\end{array}$ & Disrupts antiviral response & {$[72]$} \\
\hline CMV & Viral protein $2 b$ & $\begin{array}{l}\text { Binds to and inhibits the } \\
\text { function of AGO1; also } \\
\text { directly binds to small } \\
\text { RNAs to block } \\
\text { RISC function } \\
\text { Interacts with }\end{array}$ & Disrupts antiviral response & [73] \\
\hline TEV & $\begin{array}{c}\text { Viral helper } \\
\text { component protease }\end{array}$ & $\begin{array}{l}\text { doubled-stranded-siRNA } \\
\text { and prevents strand } \\
\text { separation }\end{array}$ & Disrupts antiviral response & [74] \\
\hline TBSV & Viral protein $\mathrm{p} 19$ & $\begin{array}{l}\text { Blocks RISC loading by } \\
\text { binding to small dsRNA } \\
\text { duplexes }\end{array}$ & Disrupts antiviral response & [75] \\
\hline RGDV & pns11 & $\begin{array}{c}\text { Upregulation of } \\
m i R-160, m i R-162, m i R- \\
167, m i R-168\end{array}$ & Increased viral pathogenesis & [76] \\
\hline
\end{tabular}


Table 2. Cont.

\begin{tabular}{ccccc}
\hline Virus & Effector Molecule & Targets of interest & Effect on virus & Reference \\
\hline \multirow{3}{*}{ PSTVd } & $m i R-396, m i R-319$, & $\begin{array}{c}\text { Transcription factors } \\
\text { associated with plant } \\
\text { morphology and } \\
\text { (downregulated) }\end{array}$ & $\begin{array}{c}\text { Increased viroid } \\
\text { pathogenesis }\end{array}$ & [77] \\
& & & \\
\hline
\end{tabular}

Though not as well studied as viral infections, bacterial infections have also been found to induce changes in host miRNA expression. Virulent, but not avirulent, mycobacterium inhibits TNF production by inducing the expression of host $m i R-125 \mathrm{~b}$, which subsequently reduces the expression of $T N F$, one of its target genes [78]. In vitro infection of epithelial cells with listeria alters the expression of five host miRNAs, $m i R-146 b, m i R-16$, let-7a, miR-145 and miR-155 [79]. Several of these miRNAs are known to regulate immune genes. Furthermore, the expression changes of these miRNAs vary between wild-type bacteria and less pathogenic mutant strains [79]. Taken together, these studies suggest that host miRNAs are also involved in bacterial pathogenesis.

\section{Counter Mechanisms to the Small RNA-Mediated Antiviral Response}

In response to the siRNA-mediated antiviral response in plants, viruses have developed counter mechanisms. Examples of these mechanisms are given in Table 1. Many plant viruses encode proteins, termed viral suppressors of RNA silencing, or VSRs [80]. Recently, the non-structural proteins (NSs) of tospoviruses were shown to bind to dsRNAs, including both siRNA duplexes and miRNA/miRNA* molecules [81]. The interaction between tomato spotted wilt virus (TSWV) NSs and dsRNA was shown to block Dicer-mediated cleavage. In addition, the binding of NSs to mature siRNA, after Dicer processing, also blocks this form of antiviral response. The $2 \mathrm{~b}$ protein of cucumber mosaic virus (CMV), a cucumovirus, possesses the ability to bind to and inhibit AGO1, thus blocking RISC function [72]. Furthermore, similar to tospovirus NSs, $2 b$ can also directly interact with small RNAs, suggesting that $2 \mathrm{~b}$ employs multiple mechanisms to block antiviral RNA silencing. The helper component protease of tobacco etch virus (TEV) is able to interact with ds-siRNA and prevent strand separation [73]. The p19 protein of tomato bushy stunt virus (TBSV) blocks RISC loading by binding small dsRNA duplexes [74]. It was recently been shown, however, that some Nicotiana plants have developed counter mechanisms to p19 RISC interference [75]. In addition to altering siRNA generation, plant VSRs can also alter host miRNA expression. Rice gall dwarf virus (RGDV), a phytoreovirus, encodes a VSR, termed Pns11 [82]. When Pns11 is individually expressed in rice, the plants display phenotypic characteristics reminiscent of RGDV-infected plants. Transgenic Pns11-expressing plants have altered levels of four host miRNAs, miR-160, miR-162, miR-167 and miR-168. The altered expression of these miRNAs, in particular, the increased expression of $m i R-167$, correlates to the disease phenotype. It has been suggested that alterations in the host gene targets of these differentially-expressed miRNAs contributes to RGDV pathogenesis. For example, the expression of a miR-167 target gene, ARF8, is altered in Pns11 transgenic plants [73]. Recently, it has been demonstrated that co-infections of plant viruses can result in more severe alterations in miRNA expression [76]. Tobacco plants co-infected with potato virus X (PVX) and either potato virus $\mathrm{Y}$ (PVY) or plum pox virus (PPV) exhibit up to a 14-fold difference in host miRNA expression 
compared to mock or singularly-infected plants. These differentially-expressed miRNAs target genes are involved in stress responses, among others, suggesting that the more dramatic alterations in host miRNA expression may be linked to the increased symptom severity of co-infected plants.

Viroids are a class of short non-coding circular single-stranded RNA (ssRNA), which infect plants and can cause disease symptoms, including growth retardation and necrosis [83]. Viroids rely entirely on host machinery for replication. As with viral infections, plants often employ siRNA-mediated immunity in response to viroid infection $[84,85]$. In viroid-infected grapevine tissues, multiple viroidderived sRNAs of $21 \mathrm{nt}, 22 \mathrm{nt}$ and $24 \mathrm{nt}$ have been found [84]. The fact, that sRNAs of varying lengths have been identified suggests that multiple DCLs, and, therefore, RNA silencing mechanisms, are involved in the host defense against viroids. For example, 60 distinct siRNA species generated from the peach latent mosaic viroid (PLMVd) ranging in size from 20 nt to 26 nt have been identified and are equally distributed between $(+)$ and $(-)$ polarities [85]. Rutgers tomato plants infected with the potato spindle tuber viroid (PSTVd) strain AS1 show disease symptoms, including necrosis and dwarfism [86]. Analysis of host small RNA expression patterns revealed that several host miRNAs, $\operatorname{miR}-159$,

$m i R-396, m i R-319$ and $m i R-403$, are downregulated in PSTVd infected plants [86]. These miRNAs are known to regulate transcription factors involved in plant morphology and development, suggesting that changes in host miRNA expression and function are associated with viroid pathogenesis.

\section{Small RNAs in Prokaryotic Immunity}

Recently, an RNAi-like defense system has been identified in prokaryotes, both bacteria and Archaea, which consists of clustered regularly-interspaced short palindromic repeats (CRISPR) and their associated (Cas) proteins [77]. The CRISPR-Cas system is considered analogous to the vertebrate adaptive immune response, as it functions in memory-based defense [87]. In CRISPR-based immunity, regions of an invading phage or plasmid, termed protospacers, are acquired and incorporated into the bacterial genome at CRISPR loci and are now called spacers [88]. It has been shown that protospacers are not randomly selected [89], but rather, there is a propensity for specific motifs in the invading DNA, such as an AAG protospacer-adjacent motif (PAM) in protospacer regions [90]. A CRISPR locus consists of a 5' leader, which functions as a recognition site for spacer incorporation [91]. The leader sequence is followed by an array spacer and repeat sequences [91]. After assembly, a precursor CRISPR RNA consisting of the leader sequence is followed by the spacer/repeat regions [92]. This precursor RNA is then processed into mature crRNA [90]. CrRNA recognize the targeted protospacer regions in foreign nucleic acid molecules, either DNA or RNA, which then leads to their degradation by specific Cas proteins [92]. CrRNA expression can be both continual and induced by the detection of foreign DNA [93]. It has been suggested that, at least in E. coli, interaction between crRNA and protospacer regions in foreign DNA can lead to a priming interaction, resulting in the attainment of new spacers [90].

Currently, three major CRISPR-Cas types, I, II and III, have been identified based on the specific Cas proteins involved in the targeted degradation of foreign nucleic acid [94]. Each CRISPR-Cas type is further divided into various subtypes. It appears that there is a plasmid/phage-specific preference in which the CRISPR-Cas subtype is activated. For example, it was recently demonstrated that sulfolobus 
islandicus rod-shaped virus 2 (SIRV2) infection of Sulfolobus islandicus preferentially induces CRISPR-Cas subtype III-B over other subtypes, such as I-A and I-D, present in the S. islandicus genome [95]. This suggests that the CRISPR-Cas system is a large and diverse acquired defense mechanism in prokaryotes. Just as eukaryotic viruses have developed several anti-RNAi defense mechanisms, it was recently shown that bacteriophages have developed anti-CRISPR strategies [96]. Genomic analysis of Pseudomonas aeruginosa-infecting phages identified five genes associated with CRISPR-Cas resistance [96]. Mutation of these genes leads to increased susceptibility of the phages to crRNA degradation. It is likely that similar anti-CRIPSR mechanisms in other bacteriophages also exist.

\section{Conclusions}

Though often through different mechanisms, small RNAs are major players in host defense and pathogen manipulation in both plants and animals (Table 1). The fact that small RNAs can alter the expression of their target genes to varying degrees makes them ideal modulators of immunity. If an immune response is too robust, it can be detrimental for the host, on the other hand, if the response is not potent enough, then the pathogen cannot be properly suppressed. Small RNAs, therefore, provide eukaryotes with the ability to fine-tune the immune system to obtain the optimal response. Pathogens, in turn, have evolved numerous ways in which to commandeer the small RNA-mediated regulatory system. Small RNAs provide pathogens with an ideal method in which to manipulate host gene expression, without triggering an anti-pathogenic response.

\section{Acknowledgements}

Support for this work was partly provided by a grant from the USDA National Institute of Food and Agriculture (AFRI 2010-65205-20452) and by the North Carolina Agricultural Research Service.

\section{Conflicts of Interest}

The authors declare no conflict of interest.

\section{References}

1. Okamura, K. Diversity of animal small RNA pathways and their biological utility. Wiley Interdiscip. Rev. RNA 2012, 3, 351-368.

2. Janga, S.C.; Vallabhaneni, S. MicroRNAs as post-transcriptional machines and their interplay with cellular networks. Adv. Exp. Med. Biol. 2011, 722, 59-74.

3. Hohn, T.; Vazquez, F. RNA silencing pathways of plants: Silencing and its suppression by plant DNA viruses. Biochim. Biophys. Acta 2011, 1809, 588-600.

4. Jaskiewicz, L.; Filipowicz, W. Role of Dicer in posttranscriptional RNA silencing. Curr. Top. Microbiol. Immunol. 2008, 320, 77-97.

5. Martínez de Alba, A.E.; Jauvion, V.; Mallory, A.C.; Bouteiller, N.; Vaucheret, H. The miRNA pathway limits AGO1 availability during siRNA-mediated PTGS defense against exogenous RNA. Nucleic Acids Res. 2011, 39, 9339-9344. 
6. Earley, K.W.; Pontvianne, F.; Wierzbick, A.T.; Blevins, T.; Tucker, S.; Costa-Nunes, P.; Pontes, O.; Pikaard, C.S. Mechanisms of HDA6-mediated rRNA gene silencing: Suppression of intergenic Pol II transcription and differential effects on maintenance versus siRNA-directed cytosine methylation. Genes Dev. 2010, 24, 1119-1132.

7. Czech, B.; Hannon, G.J. Small RNA sorting: Matchmaking for Argonautes. Nat. Rev. Genet. 2011, 12, 19-31.

8. Llave, C. Virus-derived small interfering RNAs at the core of plant-virus interactions. Trends Plant Sci. 2010, 15, 701-707.

9. Coll, N.S.; Epple, P.; Dangl, J.L. Programmed cell death in the plant immune system. Cell Death Differ. 2011, 18, 1247-1256.

10. Bittel, P.; Robatzek, S. Microbe-associated molecular patterns (MAMPs) probe plant immunity. Curr. Opin. Plant Biol. 2007, 10, 335-341.

11. Xiao, S.; Wang, W.; Yang, X. Evolution of Resistance Genes in Plants. In Innate immunity of plants, animals and humans.; Heine, H., Ed.; Springer-Verlag: Berlin, Germany, 2008; pp. 1-5.

12. Jin, H. Endogenous small RNAs and antibacterial immunity in plants. FEBS Lett. 2008, 582, 2679-2684.

13. Fahlgren, N.; Howell, M.D.; Kasschau, K.D.; Chapman, E.J.; Sullivan, C.M.; Cumbie, J.S.; Givan, S.A.; Law, T.F.; Grant, S.R.; Dangl, J.L.; et al. High-throughput sequencing of Arabidopsis microRNAs: evidence for frequent birth and death of MIRNA genes. PLoS One 2007, 2, e219.

14. Shivaprasad, P.V.; Chen, H.M.; Patel, K.; Bond, D.M.; Santos, B.A.; Baulcombe, D.C. A microRNA superfamily regulates nucleotide binding site-leucine-rich repeats and other mRNAs. Plant Cell 2012, 24, 859-874.

15. Sattar, S.; Song, Y.; Anstead, J.A.; Sunkar, R.; Thompson, G.A. Cucumis melo microRNA expression profile during aphid herbivory in a resistant and susceptible interaction. Mol. Plant Microbe Interact. 2012, 25, 839-848.

16. Katiyar-Agarwal, S.; Gao, S.; Vivian-Smith, A.; Jin, H. A novel class of bacteria-induced small RNAs in Arabidopsis. Genes Dev. 2007, 21, 3123-3134.

17. Calarco, J.P.; Martienssen, R.A. Genome reprogramming and small interfering RNA in the Arabidopsis germline. Curr. Opin. Genet. Dev. 2011, 21, 134-139

18. Kuchen, S.; Resch, W.; Yamane, A.; Kuo, N.; Li, Z.; Chakraborty, T.; Wei, L.; Laurence, A.; Yasuda, T.; Peng, S.; et al. Regulation of microRNA expression and abundance during lymphopoiesis. Immunity 2010, 32, 828-839.

19. Luers, A.J.; Loudig, O.D.; Berman, J.W. MicroRNAs are expressed and processed by human primary macrophages. Cell Immunol. 2010, 263, 1-8.

20. Forres, A.R.; Kanamori-Katayama, M.; Tomaru, Y.; Lassmann, T.; Ninomiya, N.; Takahashi, Y.; de Hoon, M.J.; Kubosaki, A.; Kaiho, A.; Suzuki, M.; et al. Induction of microRNAs, mir-155, mir-222, mir-424 and mir-503, promotes monocytic differentiation through combinatorial regulation. Leukemia 2010, 24, 460-466.

21. Dudda, J.C.; Salaun, B.; Ji, Y.; Palmer, D.C.; Monnot, G.C.; Merck, E.; Boudousquie, C.; Utzschneider, D.T.; Escobar, T.M.; Perret, R.; et al. MicroRNA-155 is required for effector CD8 ${ }^{+}$ $\mathrm{T}$ cell responses to virus infection and cancer. Immunity 2013, 38, 742-753. 
22. O’Connell, R.M.; Taganov, K.D.; Boldin, M.P.; Cheng, G.; Baltimore, D. MicroRNA-155 is induced during the macrophage inflammatory response. Proc. Natl. Acad. Sci. USA 2007, 104, 1604-1609.

23. Wang, P.; Hou, J.; Lin, L.; Wang, C.; Liu, X.; Li, D.; Ma, F.; Wang, Z.; Cao, X. Inducible microRNA-155 feedback promotes type I IFN signaling in antiviral innate immunity by targeting suppressor of cytokine signaling 1. J. Immunol. 2010, 185, 6226-6233.

24. Quinn, S.R.; O'Neill, L.A. A trio of microRNAs that control Toll-like receptor signalling. Int. Immunol. 2011, 23, 421-425.

25. O’Neill, L.A.; Sheedy, F.J.; McCoy, C.E. MicroRNAs: The fine-tuners of Toll-like receptor signalling. Nat. Rev. Immunol. 2011, 11, 163-175.

26. Li, Y.; Li, J.; Belisle, S.; Baskin, C.R.; Tumpey, T.M.; Katze, M.G. Differential microRNA expression and virulence of avian, 1918 reassortant, and reconstructed 1918 influenza A viruses. Virology 2011, 421, 105-113.

27. Vaz, C.; Mer, A.S.; Bhattacharya, A.; Ramaswamy, R. MicroRNAs modulate the dynamics of the NF-kB signaling pathway. PLoS One 2011, 6, e27774.

28. miRBase. Available online: http://www.mirbase.org/ (accessed on 26 October 2013).

29. Umbach, J.L.; Kramer, M.F.; Jurak, I.; Karnowski, H.W.; Coen, D.M.; Cullen, B.R. MicroRNAs expressed by herpes simplex virus 1 during latent infection regulate viral mRNAs. Nature. 2008, 454, 780-783.

30. Malterer, G.; Dölken, L.; Haas, J. The miRNA-targetome of KSHV and EBV in human B-cells. RNA Biol. 2011, 8, 30-34.

31. Lin, X.; Liang, D.; He, Z.; Deng, Q.; Robertson, E.S.; Lan, K. miR-K12-7-5p encoded by Kaposi's sarcoma-associated herpesvirus stabilizes the latent state by targeting viral ORF50/RTA. PLoS One 2011, 6, e16224.

32. Lu, F.; Stedman, W.; Yousef, M.; Renne, R.; Lieberman, P.M. Epigenetic regulation of Kaposi's sarcoma-associated herpesvirus latency by virus-encoded microRNAs that target Rta and the cellular Rbl2-DNMT pathway. J. Virol. 2010, 84, 2697-2706.

33. Bellare, P.; Ganem, D. Regulation of KSHV lytic switch protein expression by a virus-encoded microRNA: An evolutionary adaptation that fine-tunes lytic reactivation. Cell Host Microbe 2009, 6, 570-575.

34. Lee, S.H.; Kalejta, R.F.; Kerry, J.; Semmes, O.J.; O’Connor, C.M.; Khan, Z.; Garcia, B.A.; Shenk, T.; Murphy, E. BclAF1 restriction factor is neutralized by proteasomal degradation and microRNA repression during human cytomegalovirus infection. Proc. Natl. Acad. Sci. USA 2012, 109, 9575-9580.

35. Saffert, R.T.; Kalejta, R.F. Inactivating a cellular intrinsic immune defense mediated by DAXX is the mechanism through which the human cytomegalovirus pp71 protein stimulates viral immediate-early gene expression. J. Virol. 2006, 80, 3863-3871.

36. Morgan, R.; Anderson, A.; Bernberg, E.; Kamboj, S.; Huang, E.; Lagasse, G.; Isaacs, G.; Parcells, M.; Meyers, B.C; Green, P.J.; et al. Sequence conservation and differential expression of Marek's disease virus microRNAs. J. Virol. 2008, 82, 12213-12220.

37. Kincaid, R.P.; Burke, J.M.; Sullivan, C.S. RNA virus microRNA that mimics a B-cell oncomiR. Proc. Natl. Acad. Sci. USA 2012, 109, 3077-3082. 
38. Nachmani, D.; Stern-Ginossar, N.; Sarid, R.; Mandelboim, O. Diverse herpesvirus microRNAs target the stress-induced immune ligand MICB to escape recognition by natural killer cells. Cell Host Microbe 2009, 5, 376-385.

39. Forte, E.; Salinas, R.E.; Chang, C.; Zhou, T.; Linnstaedt, S.D.; Gottwein, E.; Jacobs, C.; Jima, D.; Li, Q.J.; Dave, S.S.; et al. The Epstein-Barr virus (EBV)-induced tumor suppressor microRNA MiR-34a is growth promoting in EBV-infected B cells. J. Virol. 2012, 86, 6889-6898.

40. Qin, Z.; Jakymiw, A.; Findlay, V.; Parsons, C. KSHV-Encoded MicroRNAs: Lessons for viral cancer pathogenesis and emerging concepts. Int. J. Cell Biol. 2012, 2012, doi:10.1155/2012/603961.

41. Lu, F.; Weidmer, A.; Liu, C.G.; Volinia, S.; Croce, C.M.; Lieberman, P.M. Epstein-Barr virus-induced miR-155 attenuates NF-kappaB signaling and stabilizes latent virus persistence. J. Virol. 2008, 82, 10436-10443.

42. Gatto, G.; Rossi, A.; Rossi, D.; Kroening, S.; Bonatti, S.; Mallardo, M. Epstein-Barr virus latent membrane protein 1 trans-activates miR-155 transcription through the NF- $\mathrm{B}$ pathway. Nucleic Acids Res. 2008, 36, 6608-6619.

43. Linnstaedt, S.D.; Gottwein, E.; Skalsky, R.L.; Luftig, M.A.; Cullen, B.R. Virally induced cellular microRNA miR-155 plays a key role in B-cell immortalization by Epstein-Barr virus. J. Virol. 2010, 84, 11670-11678.

44. Skalsky, R.L.; Samols, M.A.; Plaisance, K.B.; Boss, I.W.; Riva, A.; Lopez, M.C.; Baker, H.V.; Renne, R. Kaposi's sarcoma-associated herpesvirus encodes an ortholog of miR-155. J. Virol. 2007, 81, 12836-12845.

45. Dahlke, C.; Maul, K.; Christalla, T.; Walz, N.; Schult, P.; Stocking, C.; Grundhoff, A. A microRNA encoded by Kaposi sarcoma-associated herpesvirus promotes B-cell expansion in vivo. PLoS One. 2012, 7, e49435.

46. Sin, S.H.; Kim, Y.B.; Dittmer, D.P. Latency locus complements MicroRNA 155 deficiency in vivo. J. Virol. 2013, 87, 11908-11911.

47. Zhao, Y.; Xu, H.; Yao, Y.; Smith, L.P.; Kgosana, L.; Green, J.; Petherbridge, L.; Baigent, S.J.; Nair, V. Critical role of the virus-encoded microRNA-155 ortholog in the induction of Marek's disease lymphomas. PLoS Pathog. 2011, 7, e1001305.

48. Burnside, J.; Morgan, R. Emerging roles of chicken and viral microRNAs in avian disease. BMC Proc. 2011, 5, doi:10.1186/1753-6561-5-S4-S2.

49. Riley, K.J.; Rabinowitz, G.S.; Yario, T.A.; Luna, J.M.; Darnell, R.B.; Steitz, J.A. EBV and human microRNAs co-target oncogenic and apoptotic viral and human genes during latency. EMBO J. 2012, 31, 2207-2221.

50. Chang, T.C.; Wentzel, E.A.; Kent, O.A.; Ramachandran, K.; Mullendore, M.; Lee, K.H.; Feldmann, G.; Yamakuchi, M.; Ferlito, M.; Lowenstein, C.J.; et al. Transactivation of miR-34a by p53 broadly influences gene expression and promotes apoptosis. Mol. Cell 2007, 26, 745-752.

51. Ellis-Connell, A.L.; Iempridee, T.; Xu, I.; Mertz, J.E. Cellular microRNAs 200b and 429 regulate the Epstein-Barr virus switch between latency and lytic replication. J. Virol. 2010, 84, 10329-10343.

52. Ellis, A.L.; Wang, Z.; Yu, X.; Mertz, J.E. Either ZEB1 or ZEB2/SIP1 can play a central role in regulating the Epstein-Barr virus latent-lytic switch in a cell type-specific manner. J. Virol. 2010, 84, 6139-6152. 
53. Poole, E.; McGregor-Dallas, S.R.; Colston, J.; Joseph, R.S.; Sinclair, J. Virally induced changes in cellular microRNAs maintain latency of human cytomegalovirus in CD34+ progenitors. J. Gen. Virol. 2011, 92, 1539-1549.

54. Zheng, S.Q.; Li, Y.X.; Zhang, Y.; Li, X.; Tang, H. MiR-101 regulates HSV-1 replication by targeting ATP5B. Antiviral Res. 2011, 89, 219-226.

55. Anselmo, A.; Flori, L.; Jaffrezic, F.; Rutigliano, T.; Cecere, M.; Cortes-Perez, N.; Lefèvre, F.; Rogel-Gaillard, C.; Giuffra, E. Co-expression of host and viral microRNAs in porcine dendritic cells infected by the pseudorabies virus. PLoS One 2011, 6, e17374.

56. Lambeth, L.S.; Yao, Y.; Smith, L.P.; Zhao, Y.; Nair, V. MicroRNAs 221 and 222 target p27Kip1 in Marek's disease virus-transformed tumour cell line MSB-1. J. Gen. Virol. 2009, 90, 1164-1171.

57. Bauman, Y.; Nachmani, D.; Vitenshtein, A.; Tsukerman, P.; Drayman, N.; Stern-Ginossar, N.; Lankry, D.; Gruda, R.; Mandelboim, O. An identical miRNA of the human JC and BK polyoma viruses targets the stress-induced ligand ULBP3 to escape immune elimination. Cell Host Microbe 2011, 9, 93-102.

58. Sullivan, C.S.; Sung, C.K.; Pack, C.D.; Grundhoff, A.; Lukacher, A.E.; Benjamin, T.L.; Ganem, D. Murine Polyomavirus encodes a microRNA that cleaves early RNA transcripts but is not essential for experimental infection. Virology 2009, 387, 157-167.

59. Sullivan, C.S.; Grundhoff, A.T.; Tevethia, S.; Pipas, J.M.; Ganem, D. SV40-encoded microRNAs regulate viral gene expression and reduce susceptibility to cytotoxic T cells. Nature 2005, 435, 682-686.

60. Chen, C.J.; Kincaid, R.P.; Seo, G.J.; Bennett, M.D.; Sullivan, C.S. Insights into Polyomaviridae microRNA function derived from study of the bandicoot papillomatosis carcinomatosis viruses. J. Virol. 2011, 85, 4487-4500.

61. Huang, J.; Wang, F.; Argyris, E.; Chen, K.; Liang, Z.; Tian, H.; Huang, W.; Squires, K.; Verlinghieri, G.; Zhang, H. Cellular microRNAs contribute to HIV-1 latency in resting primary CD4 ${ }^{+}$T lymphocytes. Nat. Med. 2007, 13, 1241-1247.

62. Li, Z.; Zhang, S.; Huang, C.; Zhang, W.; Hu, Y.; Wei, B. MicroRNAome of splenic macrophages in hypersplenism due to portal hypertension in hepatitis B virus-related cirrhosis. Exp. Biol. Med. 2008, 233, 1454-1461.

63. Li, Y.; Chan, E.Y.; Li, J.; Ni, C.; Peng, X.; Rosenzweig, E.; Tumpey, T.M.; Katze, M.G. MicroRNA expression and virulence in pandemic influenza virus-infected mice. J. Virol. 2010, 84, 3023-3032.

64. Loveday, E.K.; Svinti, V.; Diederich, S.; Pasick, J.; Jean, F. Temporal- and strain-specific host microRNA molecular signatures associated with swine-origin $\mathrm{H} 1 \mathrm{~N} 1$ and avian-origin H7N7 influenza A virus infection. J. Virol. 2012, 86, 6109-6122.

65. Grinberg, M.; Gilad, S.; Meiri, E.; Levy, A.; Isakov, O.; Ronen, R.; Shomron, N.; Bentwich, Z.; Shemer-Avni, Y. Vaccinia virus infection suppresses the cell microRNA machinery. Arch. Virol. 2012, 157, 1719-1727.

66. Kakumani, P.K.; Ponia, S.S.; Rajgokul, K.S.; Sood, V.; Chinnappan, M.; Banerjea, A.C.; Medigeshi, G.R.; Malhotra, P.; Mukherjee, S.K.; Bhatnagar, R.K. Role of RNA Interference (RNAi) in dengue virus replication and identification of NS4B as an RNAi suppressor. J. Virol. 2013, 87, 8870-8883. 
67. Jopling, C.L.; Yi, M.; Lancaster, A.M.; Lemon, S.M.; Sarnow, P. Modulation of hepatitis C virus RNA abundance by a liver-specific MicroRNA. Science 2005, 309, 1577-1581.

68. Lewis, A.P.; Jopling, C.L. Regulation and biological function of the liver-specific miR-122. Biochem. Soc. Trans. 2010, 38, 1553-1557.

69. Fukuhara, T.; Kambara, H.; Shiokawa, M.; Ono, C.; Katoh, H.; Morita, E.; Okuzaki, D.; Maehara, Y.; Koike, K.; Matsuura, Y. Expression of MicroRNA miR-122 Facilitates an Efficient Replication in Nonhepatic Cells upon Infection with Hepatitis C Virus. J. Virol. 2012, 86, 7918-7933.

70. Norman, K.L.; Sarnow, P. Modulation of hepatitis C virus RNA abundance and the isoprenoid biosynthesis pathway by microRNA miR-122 involves distinct mechanisms. J. Virol. 2010, 84, 666-670.

71. Shimakami, T.; Yamane, D.; Welsch, C.; Hensley, L.; Jangra, R.K.; Lemon, S.M. Base pairing between hepatitis C virus RNA and microRNA 122 3' of its seed sequence is essential for genome stabilization and production of infectious virus. J. Virol. 2012, 86, 7372-7383.

72. González, I.; Martínez, L.; Rakitina, D.V.; Lewsey, M.G.; Atencio, F.A.; Llave, C.; Kalinina, N.O.; Carr, J.P.; Palukaitis, P.; Canto, T. Cucumber mosaic virus 2b protein subcellular targets and interactions: Their significance to RNA silencing suppressor activity. Mol. Plant Microbe Interact. 2010, 23, 294-303.

73. Kataya, A.R.; Suliman, M.N.; Kalantidis, K.; Livieratos, I.C. Cucurbit yellow stunting disorder virus p25 is a suppressor of post-transcriptional gene silencing. Virus Res. 2009, 145, 48-53.

74. Ahn, J.W.; Lee, J.S.; Davarpanah, S.J.; Jeon, J.H.; Park, Y.I.; Liu, J.R.; Jeong, W.J. Host-dependent suppression of RNA silencing mediated by the viral suppressor p19 in potato. Planta 2011, 234, 1065-1072.

75. Sansregret, R.; Dufour, V.; Langlois, M.; Daayf, F.; Dunoyer, P.; Voinnet, O.; Bouarab, K. Extreme resistance as a host counter-counter defense against viral suppression of RNA silencing. PLoS Pathog. 2013, 9, e1003435.

76. Pacheco, R.; García-Marcos, A.; Barajas, D.; Martiáñez, J.; Tenllado, F. PVX-potyvirus synergistic infections differentially alter microRNA accumulation in Nicotiana benthamiana. Virus Res. 2012, $165,231-235$.

77. Maier, L.K.; Fischer, S.; Stoll, B.; Brendel, J.; Pfeiffer, F.; Dyall-Smith, M.; Marchfelder, A. The immune system of halophilic archaea. Mob. Genet. Elements 2012, 2, 228-232.

78. Rajaram, M.V.; Ni, B.; Morris, J.D.; Brooks, M.N.; Carlson, T.K.; Bakthavachalu, B.; Schoenberg, D.R.; Torrelles, J.B.; Schlesinger, L.S. Mycobacterium tuberculosis lipomannan blocks TNF biosynthesis by regulating macrophage MAPK-activated protein kinase 2 (MK2) and microRNA miR-125b. Proc. Natl. Acad. Sci. USA 2011, 108, 17408-17413.

79. Izar, B.; Mannala, G.K.; Mraheil, M.A.; Chakraborty, T.; Hain, T. microRNA Response to Listeria monocytogenes Infection in Epithelial Cells. Int. J. Mol. Sci. 2012, 13, 1173-1185.

80. Burgyán, J.; Havelda, Z. Viral suppressors of RNA silencing. Trends Plant Sci. 2011, 16, 265-272.

81. Pantaleo, V.; Saldarelli, P.; Miozzi, L.; Giampetruzzi, A.; Gisel, A.; Moxon, S.; Dalmay, T.; Bisztray, G.; Burgyan, J. Deep sequencing analysis of viral short RNAs from an infected Pinot Noir grapevine. Virology 2010, 408, 49-56.

82. Shen, W.J.; Ruan, X.L.; Li, X.S.; Zhao, Q.; Li, H.P. RNA silencing suppressor Pns11 of rice gall dwarf virus induces virus-like symptoms in transgenic rice. Arch. Virol. 2012, 157, 1531-1539. 
83. Ding, B. Viroids: Self-replicating, mobile, and fast-evolving noncoding regulatory RNAs. Wiley Interdiscip. Rev. RNA 2010, 1, 362-375.

84. Navarro, B.; Pantaleo, V.; Gisel, A.; Moxon, S.; Dalmay, T.; Bisztray, G.; di Serio, F.; Burgyán, J. Deep sequencing of viroid-derived small RNAs from grapevine provides new insights on the role of RNA silencing in plant-viroid interaction. PLoS One 2009, 4, e7686.

85. St-Pierre, P.; Hassen, I.F.; Thompson, D.; Perreault, J.P. Characterization of the siRNAs associated with peach latent mosaic viroid infection. Virology 2009, 383, 178-182.

86. Diermann, N.; Matoušek, J.; Junge, M.; Riesner, D.; Steger, G. Characterization of plant miRNAs and small RNAs derived from potato spindle tuber viroid (PSTVd) in infected tomato. Biol. Chem. 2010, 391, 1379-1390.

87. Makarova, K.S.; Wolf, Y.I.; Koonin, E.V. Comparative genomics of defense systems in archaea and bacteria. Nucleic Acids Res. 2013, 41, 4360-4377.

88. Szczepankowska, A. Role of CRISPR/cas system in the development of bacteriophage resistance. Adv. Virus Res. 2012, 82, 289-338.

89. Westra, E.R.; Staals, R.H.; Gort, G.; Høgh, S.; Neumann, S.; de la Cruz, F.; Fineran, P.C.; Brouns, S.J. CRISPR-Cas systems preferentially target the leading regions of MOBF conjugative plasmids. RNA Biol. 2013, 10, 749-761.

90. Savitskaya, E.; Semenova, E.; Dedkov, V.; Metlitskaya, A.; Severinov, K. High-throughput analysis of type I-E CRISPR/Cas spacer acquisition in E. coli. RNA Biol. 2013, 10, 716-725.

91. Han, P.; Niestemski, L.R.; Barrick, J.E.; Deem, M.W. Physical model of the immune response of bacteria against bacteriophage through the adaptive CRISPR-Cas immune system. Phys. Biol. 2013, 10, doi:10.1088/1478-3975/10/2/025004.

92. Lange, S.J.; Alkhnbashi, O.S.; Rose, D.; Will, S.; Backofen, R. CRISPRmap: An automated classification of repeat conservation in prokaryotic adaptive immune systems. Nucleic Acids Res. 2013, 41, 8034-8044.

93. Cai, F.; Axen, S.D.; Kerfeld, C.A. Evidence for the widespread distribution of CRISPR-Cas system in the Phylum Cyanobacteria. RNA Biol. 2013, 10, 687-693.

94. Díez-Villaseñor, C.; Guzmán, N.M.; Almendros, C.; García-Martínez, J.; Mojica, F.J. CRISPR-spacer integration reporter plasmids reveal distinct genuine acquisition specificities among CRISPR-Cas I-E variants of Escherichia coli. RNA Biol. 2013, 10, 792-802.

95. Jaubert, C.; Danioux, C.; Oberto, J.; Cortez, D.; Bize, A.; Krupovic, M.; She, Q.; Forterre, P.; Prangishvili, D.; Sezonov, G. Genomics and genetics of Sulfolobus islandicus LAL14/1, a model hyperthermophilic archaeon. Open Biol. 2013, 3, doi:10.1098/rsob.130010.

96. Bondy-Denomy, J.; Pawluk, A.; Maxwell, K.L.; Davidson, A.R. Bacteriophage genes that inactivate the CRISPR/Cas bacterial immune system. Nature 2013, 493, 429-432.

(C) 2013 by the authors; licensee MDPI, Basel, Switzerland. This article is an open access article distributed under the terms and conditions of the Creative Commons Attribution license (http://creativecommons.org/licenses/by/3.0/). 